\title{
Evaluation of Inter-fiber Bonding in Wood Pulp Fibers by Chemical Force Microscopy
}

\author{
Dongbo Yan ${ }^{1,2} \&$ Kecheng $\mathrm{Li}^{1}$ \\ ${ }^{1}$ Department of Chemical Engineering, University of New Brunswick, Fredericton, Canada \\ ${ }^{2}$ Pulp and Paper Division, FPInnovations, Vancouver, Canada \\ Correspondence: Dongbo Yan, Pulp and Paper Division, FPInnovations, 3800 Wesbrook mall, Vancouver, BC, \\ V6S 2L9, Canada. Tel: 1-604-225-5810. E-mail: Dongbo.Yan@FPInnovations.ca
}

\author{
Received: September 11, 2012 Accepted: October 10, 2012 Online Published: October 16, 2012 \\ doi:10.5539/jmsr.v2n1p23 URL: http://dx.doi.org/10.5539/jmsr.v2n1p23
}

\begin{abstract}
Atomic force microscopy with chemically modified tips was used to evaluate the inter fiber bonding properties of typical wood pulp fibers. Using - OH functionalized AFM tips as a model of cellulosic pulp fiber surfaces, pull-off forces and work of adhesion were measured in aqueous media. Three distinct tip-surface interactions were identified from force-displacement curves, representing three typical surface conditions of wet pulp fiber surfaces: solid, swollen and micro-fibrillated. The work of adhesion calculated shows that van der Waals forces are the major contributing factor on non-swollen solid regions of fiber surfaces. The difference in inter-molecular bond strength of different pulp fibers was relatively small. The inter-fiber bonding properties of pulp fibers were mainly controlled by the surface deformability, which determined the area of molecular contact at fiber-fiber physical interaction points.
\end{abstract}

Keywords: chemical force microscopy, wood pulp fibers, adhesion

\section{Introduction}

In a paper sheet, individual fibers are held together by van der Waals forces and hydrogen bonds, providing paper with the essential structural and mechanical strength. Inter-fiber bonding strength is particularly important when using low-cost high yield pulp fibers (HYP) together with softwood bleached kraft pulp fibers (SBKP) in making traditional wood free paper products.

HYP refers to those pulps produced by thermo-mechanical pulping (TMP) and chemi-thermo-mechanical pulping (CTMP) processes. Unlike SBKP fibers that mainly consist of pure cellulose and hemicellulose, most wood components, such as lignin and extractives, still remain in HYPs. Therefore, HYP fibers are usually more hydrophobic and stiffer, thus less deformable, leading to poor inter-fiber bond strength compared to SBKP fibers. In order to further increase the use of HYP fibers in high end paper products, it is essential to understand the differences in inter-fiber bond properties between HYP and SBKP.

The fiber-fiber bond structure is considered to be an adhesive joint. The bonding properties are determined by the strength of inter-molecular interactions, the number of interactions within the area and the total area in molecular contact (Mark, 2002; Retulainen, Niskanen, \& Nilsen, 1998). HYP fibers are stiffer and less conformable than chemical pulp fibers, leading to a smaller area of molecular contact at the fiber-fiber interface. Furthermore, the strength of inter-molecular interactions of HYP fiber surfaces is also different due to variations in surface chemistry. The inter-fiber bonding properties of pulp fibers are mainly influenced by these two factors, which are a function of pulping methods, refining and chemical treatment (Mohlin, 1974; Nordman, Gustafsson, \& Olofsson, 1954; Skowronski \& Bichard, 1987; Uesaka, 1984). However, the effect of the two factors on the strength of the fiber network is difficult to determine separately due to the lack of measurement methods. As a result, even though the inter-fiber bonding properties of wood fibers have been studied extensively since the 1950's (Mohlin, 1974; Retulainen \& Ebeling, 1985; Skowronski \& Bichard, 1987), “our understanding of the molecular mechanisms of bonding is still in its infancy" (Lindstrom, Wagberg, \& Larrson, 2005).

The main objective of this study is to quantitatively determine the strength of inter-molecular interactions for different types of pulp fibers. Numerous methods have been proposed for quantifying the inter-fiber bond strength of pulp fibers. Holmberg (1997) used a surface force apparatus (SFA) to determine the adhesion 
between surfaces of Langmuir Blodgett (LB) cellulose films in dry air. The interfacial energy of the cellulose surfaces has been found to be between 53 and $106 \mathrm{mN} / \mathrm{m}$. Notley et al. (Notley, Pettersson, \& Wagberg, 2004) used colloidal probe atomic force microscopy to measure the interaction between a $13.5 \mu \mathrm{m}$ radius regenerated cellulose microsphere and a regenerated cellulose film in water, then calculated the Hamaker constant of cellulose. However, these forces measured are not specific because they are strongly influenced by the nature of surface roughness of the cellulose film, colloidal probe and fiber surfaces. Chemical Force Microscopy (CFM) is a variation of AFM in which an AFM-tip is modified with self-assembling monolayers (SAMs) (Noy, Vezenov, \& Lieber, 1997). The SAMs are usually alkanethiol compounds terminated with $-\mathrm{CH} 3,-\mathrm{COOH}$ and $-\mathrm{OH}$ functional groups. The adhesion between the modified tip and surfaces to be measured can be used as a tool to investigate the strength of inter-molecular interactions at a nanometer resolution (Bastidas et al., 2005; Papastavrou \& Akari, 2000; Vezenov, Noy, Rozsnyai, \& Lieber, 1997). Generally, the fully bleached chemical pulp fiber surface can be modeled with an AFM tip coated with -OH terminated SAM. Since the curvature radius of AFM tips is much smaller than the typical asperities on natural fiber surfaces, the adhesion measure with the CFM is considered to be a specific interaction (Willing \& Neuman, 2002). Bastidas et al (Bastidas et al., 2005) investigated the differences in adhesion forces between bleached softwood kraft pulp fibers and modified ATM tips coated with $-\mathrm{OH},-\mathrm{CH} 3$ and $-\mathrm{COOH}$ groups. They found that the adhesion between $-\mathrm{OH}$ functionalized tips and chemical fiber surfaces was about $1 \mathrm{nN}$ and was not affected by $\mathrm{pH}$ level. Klash et al (Klash, Ncube, \& Meincken, 2009a) used CFM with similar functionalized tips to image and localize different chemical components on wood fiber surfaces in air. The distinction between lignin and cellulose was achieved mainly due to the difference in the degree of polarity of these components (Klash, Ncube, \& Meincken, 2009b). The adhesive force reported in air varies from $\sim 300 \mathrm{nN}$ to $\sim 1400 \mathrm{nN}$, which mainly come from capillary forces. In order to eliminate the capillary forces caused by the layer of condensed water on the surface, force measurements are usually conducted in liquid environments. Furthermore, wood pulp fiber surfaces are usually negatively charged (Davison \& Cates, 1975). This surface charge and double-layer interaction forces in water can also be removed by adjusting the ionic strength of the solution. Under controlled conditions, the adhesion due only to the van der Waals and hydrogen-bonding interactions between the tip and the fiber surfaces were measured (Feldman, Tervoort, Smith, \& Spencer, 1998). However, most of these studies were performed on fully bleached chemical pulp fibers, which mainly consist of cellulose and hemicelluloses. The surfaces of HYP fibers are much more complex than the surfaces of chemical pulp fibers not only in chemical composition, but also in surface topography. When HYP fibers are blended with chemical fibers, the inter-fiber bonding strength between these two types of fibers is equally important for overall strength development.

In this study, the cellulosic fiber surface of a fully bleached chemical fiber was simulated by AFM-tips modified with -OH terminated SAMs. Force-distance curve measurements were performed in water under a controlled environment. Rupture force, rupture distance and work of adhesion were measured on some typical commercial wood HYP fibers, in order to study the effects of different pulping methods on the inter-fiber bonding properties of the resulting fibers.

\section{Experimental}

\subsection{Materials}

Bleached spruce kraft pulp (SBKP), aspen chemi-thermo-mechanical pulp (ACTMP) and two bleached ACTMP pulps, high tensile grade(AHT) and high bulk grade (AHB) obtained from Tembec Inc. (Temiscamingue, QC, Canada) were used in this study. AHT pulp was bleached under higher alkali conditions than the AHB in order to increase fiber conformability (Michael, Bo, \& Gorgen, 1985; Pan, 2001). AHT and AHB pulps were further refined with a PFI mill at $3 \%$ consistency to 3000 revolutions. These refined pulps were denoted as AHTLCR and AHBLCR, respectively. SBKP pulp was also refined to 6000 revaluations with a PFI mill at $10 \%$ consistency and denoted as SBKPPFI. A commercial spruce thermo-mechanical pulp (STMP) was also used in this study.

\subsection{Sample Preparation}

Pulp samples $(0.3 \mathrm{~g}$ o.d) were diluted to $0.03 \%$ consistency and drained onto a piece of filter paper (Fisher brand Q8) with a TAPPI standard hand sheet former. Pulp fibers were then transferred onto a cover slip by placing and gently tapping the filter paper onto the cover slip. Water present on the cover slip was allowed to evaporate until free water was no longer visible. A glass slide (Fisher brand pre-cleaned microscope slide) was coated with a thin layer of solvent-free epoxy resin (Devcon, 5 minutes Epoxy). All excess resin was removed using a blade so that only a very thin resin layer remained on the slide to ensure fibers would only be glued on one side rather than being embedded. The cover slip with fibers was placed on the glass slide. Once the cover slip was removed, 
some fibers remained fixed in the epoxy resin on the glass slide. When the epoxy cured, the glass slide was immersed in deionized water for use.

\subsection{Tip Modification}

Silicon Nitride AFM probes with thin gold/chromium film coated rectangular cantilevers (Olympus OMCL-RC800PB) were used for chemical modification. The nominal radius of the tip is $30 \mathrm{~nm}$ and nominal spring constants of 4 cantilevers on the same chip are $0.82,0.42,0.11$ and $0.06 \mathrm{~N} / \mathrm{m}$. AFM cantilevers for modification were exposed to a $254 \mathrm{~nm}$ UV lamp for 1 hour to remove any organic contaminants on the tip surface. The tips were kept in a $1 \mathrm{mM}$ ethanolic solution of 11-mercapto-1-undecanol [HS- $(\mathrm{CH} 2) 11-\mathrm{OH}$ ] (Aldrich)for 12 hour. The tips were then rinsed with alcohol, dried and kept in pure nitrogen gas for later use.

\subsection{AFM Adhesion Force Measurement}

Force displacement curve measurements were performed with a standalone AFM (MPF-3D, Asylum Research, Santa Barbara, USA). All measurements were carried out at room temperature in aqueous solutions. The ionic strength of the solutions was adjusted with $\mathrm{NaCl}$ to $0.1 \mathrm{~mol} / \mathrm{L}$. The $\mathrm{pH}$ was adjusted with $0.01 \mathrm{~m} \mathrm{~mol} / \mathrm{L} \mathrm{HCl}$ to 4.2. The cantilever with $0.42 \mathrm{~N} / \mathrm{m}$ nominal spring constant was used for force measurement of adhesion while others were used for fiber surface imaging. The spring constant of cantilever used for force measurement was calculated from the thermal noise of the cantilever with the built-in function of the MPF-3D software (Proksch \& Cleveland, 2005). The sensitivity of the cantilever was recalibrated by pushing the AFM tip against the surface of a glass slide in water.

The glass slides with fibers were soaked in a solution for 30 minutes prior to conducting AFM measurements. Topography mapping of fibers was obtained using the contact mode in order to locate a relatively flat area for force measurement. Using the force mapping function provided with the software, 16 points were measured over a $5 \times 5 \mu \mathrm{m}$ scan area. At least 10 fibers were measured in each pulp sample.

In order to reduce the variability of the measurement, a relative force trigger of $250 \mathrm{pN}$ was used. Tip scan speed was set to $400 \mathrm{~nm} / \mathrm{s}$. A two second dwell time was used for keeping the tip and fibers in contact at Fmax $=250 \mathrm{pN}$ before the tip jumps off the fiber surface. The maximum force when pulling the tip out of fiber surfaces was defined as the rupture force. Any distorted force curves due to failed tip engagement to fiber surfaces or interference by micro-fibrils on the fiber surfaces were removed manually prior to calculating adhesion energy. The adhesion data was represented as the average of effective measurements of all samples with standard errors.

\section{Results and Discussion}

\subsection{Typical Force-displacement Curves on Wood Pulp Fibers}

Unlike dry pulp fibers, the surface of wet wood fibers in water is much more complicated. For HYP fibers, the chemical composition on the surface depends strongly on the location at which the fiber is separated during refining. It might be lignin if the fibers were separated at the middle lamella or cellulose if separation occurred within the secondary fiber wall. The surface morphology also varies from location to location depending on the fiber separation point, and also depending on the mechanical treatment used to separate these fibers. It may be smooth, granular or fully fibrillated. For chemical pulp fibers, the surface might also be a solid substrate, or a water-swollen compliance layer, or fully fibrillated. Some of these surface conditions are illustrated in Figure 1 $(a, b, c)$, which are typical SEM images of some wood pulp fibers used in this study.

Three distinct types of tip-surface interactions were observed on force-displacement curves obtained in water as shown in Figure 2. The difference can be found in the rupture distance and the number of ruptures on the retraction curve. Type I interaction has only a single rupture occurring in the retraction part of the force-displacement curve. The rupture force corresponds to the breaking of inter-molecular interactions that formed between the -OH functionalized tip and the fiber surface (Papastavrou \& Akari, 2000). The distances between the tip jump-to-contact and jump-off point of this type of interaction observed for all fibers are usually less than $20 \mathrm{~nm}$, which suggests a solid, non-deformable surface area of the fiber wall. This type of interaction can be considered as a sharp AFM tip measuring a flat surface since the curvature radius of the tip is usually smaller than the typical asperities on fiber surfaces (Willing \& Neuman, 2002). Because the contact area is well defined in this case, the work of adhesion required to separate the tip and the fiber surface can be calculated according to the Johnson-Kendall-Roberts (JKR) model.

A typical type II adhesion observed has two ruptures within a certain distance. This suggests that the tip engaged the swollen, gel-like compliant surface where micro-fibrils on the fiber surface were loosened by the water molecules (Furuta \& Gray, 1998; Neuman, Berg, \& Claesson, 1993; Zauscher \& Klingenberg, 2000). The first rupture indicates a plastic yield of the gel-like layer while the tip is being pulled off the surface. The second 
rupture represents the breaking of inter-molecular interactions between the AFM tip and the fiber surface, which has a higher amplitude than that of the first rupture.

Type III curves have multiple ruptures during tip retraction. This indicates that the fiber surface is covered with a layer of loosened micro-fibrils. These micro-fibrils are protruding out from the fiber surface and extend into the solution (Neuman et al., 1993), but collapse and form a loose pad on the fiber surface when the ionic strength is high (Furuta \& Gray, 1998). The AFM tip easily penetrates into the loose pad of micro-fibrils when it engages with the surface. Multiple micro-fibrils may come in contact with the tip and bind to it. Beside the interactions observed in type II, breaking of individual binding interactions occurs as discrete events during the retraction of the AFM tip. Micro fibrils can also be picked up and unfolded by the AFM tip; therefore the rupture distance of this type of interaction may be as far as $1 \mu \mathrm{m}$. Figure 1 shows the SEM images of three typical pulp fibers used in this study, indicating possible locations where type I, II and III tip-surface interactions likely occur.

\subsection{Specific Adhesion of Wood Pulp Fibers}

During a type I interaction, the AFM tip engages with a solid, less swollen area on the fiber surface. Since the nominal radius of the tip is only $30 \mathrm{~nm}$, type I interactions can be considered as an AFM tip on a flat elastic substrate. When only short range forces inside the contact region are considered, the pull-off force is given with the JKR equation (Johnson, Kendall, \& Roberts, 1971), which is

$$
F_{a d}=\frac{3}{2} \pi R W_{a d}
$$

Where $R$ is the radius of the tip and $W_{a d}$ is the work of adhesion of two different bodies, which are the AFM tip and the fiber surface.

The pull-off force measured by using the -OH functionalized tip on wood pulp fibers in this study varies from $0.29 \mathrm{nN}$ to $1.08 \mathrm{nN}$. This agrees fairly well with values found in literature, $0.32 \pm 0.14 \mathrm{nN}$, which was obtained with the - $\mathrm{OH}$ functionalized tips and the-OH terminated surface in water (Bastidas et al., 2005).

Work of adhesion, $W_{a d}$, calculated using Equation (1) for all pulp fibers, are listed in Table 1. Because of the very high dielectric constant and competition of water molecules for free $-\mathrm{OH}$ groups, the adhesion force between the $-\mathrm{OH}$ groups is reduced significantly (Papastavrou \& Akari, 2000). If both the AFM and the fiber surface are approximated as pure cellulose, the work of adhesion is then given by (Isrealachvilli, 1991)

$$
W_{a d}=2 \gamma_{\text {cellulose }}
$$

The Van der Waals contribution to the surface energy $\gamma_{\text {cellulose }}$ can be estimated from the Hamaker constant. The work of adhesion, $W_{\text {cellulose }}$, was calculated from the following approximation (Feldman et al., 1998; Isrealachvilli, 1991):

$$
W_{\text {cellulose }}=2 \gamma_{\text {cellulose }}=\frac{H}{12 \pi D_{0}^{2}}
$$

Where $D_{0}$ is the cut-off distance. A typical value of this is $0.165 \mathrm{~nm}$ (Isrealachvilli, 1991). The Hamaker constant of cellulose determined in an aqueous environment is reported to be about of $7.2 \times 10^{-21} \mathrm{~J}$ to of $9.0 \times 10^{-21} \mathrm{~J}$ (Holmberg et al., 1997; Notley et al., 2004; Osterberg \& Claesson, 2000). This yields the work of adhesion of two cellulose surfaces calculated as about $W_{\text {cellulose }}=7.0 \mathrm{~mJ} / \mathrm{m}^{2}$ if a Hamaker constant of $7.2 \times 10^{-21} \mathrm{~J}$ is used.

From the results obtained on different pulp fibers that are listed in Table 1, it can be seen that only the specific adhesion of SBKPPFI fibers, $W_{a d}=7.7 \mathrm{~mJ} / \mathrm{m}^{2}$ is close to the theoretical van der Waals adhesion of pure cellulose surfaces. The SBKPPFI fibers are fully refined, fully bleached kraft pulp fibers, which can be considered as a surface consisting of pure carbohydrates. However, the adhesion of unrefined SBKP is much lower than that of SBKPPFI. A possible reason for the difference is the lignin absorption on the fiber surface (Li \& Reeve, 2002, 2000). This thin layer of lignin can be removed easily by mechanical refining. According to our previous study using modeled lignin and cellulose (Tan \& Li, 2008), the specific adhesion of lignin- cellulose is only about $1 / 3$ of the adhesion of a cellulose-cellulose system. This can also be confirmed by the $W_{a d}$, measured on the CTMP and TMP fibers, which are about $1 / 3$ of $W_{\text {cellulose }}$. The TMP and the CTMP fibers are separated mainly along the middle lamella of the cell walls during pulping. These fibers have a smooth lignin layer on the surface as can be seen in Figure 1 because fibers are separated just below the lignin glass transition temperature. During peroxide bleaching, part of the hydrophobic substances, such as lignin and extractives on fiber surfaces, have been 
removed or oxidized (Pan, 2003), which promotes the ability to form hydrogen bonds. As a result, higher adhesion is found for AHB and AHT fibers. This also confirms that bleaching of CTMP fibers promotes inter-fiber bonding strength by improving specific bond strength (Pan, 2001). Mechanical refining also removes lignin from the fiber surface, exposing cellulose, thus adhesion is also improved through refining as can be seen for AHTLCR and AHTLCR.

Table 1. List of mean values of all three adhesion types measured with -OH functionalized tips in water as well as hand sheet Scott bond strength

\begin{tabular}{|c|c|c|c|c|c|c|c|c|}
\hline & АCTMP & AHB & AHT & AHBLCR & AHTLCR & SBKP & SBKPPFI & TMP \\
\hline Work of adhesion & 2.03 & 2.02 & 3.88 & 3.47 & 4.23 & 3.24 & 7.66 & 2.22 \\
\hline $\mathrm{mN} / \mathrm{m}$ & $(0.16)$ & $(0.20)$ & $(0.35)$ & $(0.48)$ & $(0.52)$ & $(0.36)$ & (1.78) & $(0.20)$ \\
\hline Pull-off work of type & 7.17 & 11.50 & 18.66 & 13.75 & 17.80 & 19.79 & 69.14 & 9.09 \\
\hline$I, x^{18} J$ & $(1.25)$ & $(2.70)$ & $(3.77)$ & $(1.72)$ & (2.11) & $(2.62)$ & $(12.40)$ & $(0.97)$ \\
\hline Pull-off work of type & 39.03 & 39.60 & 71.96 & 70.53 & 76.23 & 79.57 & 322.62 & 52.21 \\
\hline $\mathrm{II}, x^{18} J$ & $(4.24)$ & $(25.80)$ & $(8.24)$ & (11.85) & $(9.02)$ & $(22.25)$ & (71.93) & $(11.90)$ \\
\hline Pull-off work of type & 100.16 & 165.73 & 288.81 & 847.55 & 905.92 & & 951.53 & 77.90 \\
\hline III,$x^{18} J$ & (38.89) & (17.46) & $(34.78)$ & $(160.25)$ & & - & (131.02) & (12.05) \\
\hline $\begin{array}{l}\text { Scott Internal Bond } \\
\text { Strength }(\mathrm{J} / \mathrm{m} 2)\end{array}$ & 16.4 & 16.2 & 22.4 & 17.0 & 31.0 & 44.4 & 160.2 & 20.7 \\
\hline
\end{tabular}

\subsection{Effect Ofinter-fiber Bonding Properties on Sheet Strength}

The sheet strength was evaluated using Scott internal bond strength (SBS) measured on fines-free handsheets made of these pulps. The results are listed in Table 1. The SBS of handsheets shows a good correlation to the work of adhesion calculated on Type I interactions as shown in Figure 4. However, the difference in SBS is much higher than the difference in $W_{a d}$ among these pulp fibers. The SBS also shows stronger correlation to the pull off work of type I interactions. The $W_{a d}$ was calculated solely from the rupture force. The pull-off work is an integration of pull-off force and rupture distance, which is a function of the deformability of fiber surface. High correlation has also been found between the SBS and the pull of work of type II interactions of these pulp fibers as shown in Figure 6, which also suggests the importance of the deformability of the fiber surface. However, the pull-off work is measured on wet fibers whereas the SBS is measured on dry sheets. Since the deformability of dry fibers is much lower than the wet pulp fibers in term of elastic modulus (Mark, 2002), the difference in SBS is not likely coming from the difference of deformability of dry fibers. Therefore beside the difference in the $W_{a d}$, the large variationin the SBS can only be explained by the difference in the area of molecular contact and entanglement of micro fibrils.

During a typical papermaking process, pulp fibers are pulled into contact by capillary forces, large real contacts at fiber-fiber crossings can only be formed when the wet fibers have high deformability (Lindstrom et al., 2005; Theo \& van de Ven, 2008). It can be seen in Figure 2 that the pull-off work of type II interactions is highly related to the deformability of wet fiber surfaces. Therefore it also shows a high correlation to the SBS of the dry sheet.The work of pull-off adhesion of the type II interaction shows a certain dependence on the chemical and the mechanical treatment to the fibers as shown in Figure 7. This comes mainly from the difference in rupture distances that is determined by the thickness of the compliant layer on the surface of wet fibers, or the degree of swelling, which is significantly affected by refining (Chhabra, Spelt, Yip, \& Kortschot, 2005). It has been reported that no or very weak adhesion forces have been observed when it is measured with a cellulosic colloidal probe on cellulose surfaces in water (Nigmatullin et al., 2004; Zauscher \& Klingenberg, 2000) because there is less swelling and lower deformability of the cellulose bead. Therefore, the ability to deform and to form areasof molecular contact is a key factor that determines inter-fiber bonding properties of wood pulp fibers.

Type III interactions were due to micro fibrils on the wet fiber surface. When dried, these micro fibrils are bonded to the fiber surface (Page \& Sargent, 1961). Therefore, it is unlikely that the micro fibrils would peel off and unfold from the dry fibers. However, these micro fibrils play a very important role in forming inter-fiber bonds. During the paper making process, fibrils are brought into close contact under surface tension, and then 
re-adhere to the surfaces of base fibers and adjacent fibers, thus allowing inter-molecular bonds to form between the entangled fibrils and fiber surfaces (Clark, 1985; Mark, 2002). Even though the pull-off work measured on this type of interaction cannot be used directly for evaluating inter-fiber bond strength, the occurrence can be used to estimate the surface coverage of micro fibrils between pulp fibers. The percentage of type I, II and III interaction occurrence measured for all fibers is summarized in Figure 8. For HYP fibers separated with a minor chemical treatment (ACTMP) or without any chemical treatment (TMP), the percentage of type III interactions observed is very small. It is also small for the SBKP fibers without any mechanical treatment. This explains why these fibers have similar $W_{a d}$ and pull-off work of type I interaction to AHT, AHB, AHTLCR and AHBLCR fibers, but have much lower SBS due to the lack of external micro fibrils for forming additional inter-fiber bonding area.
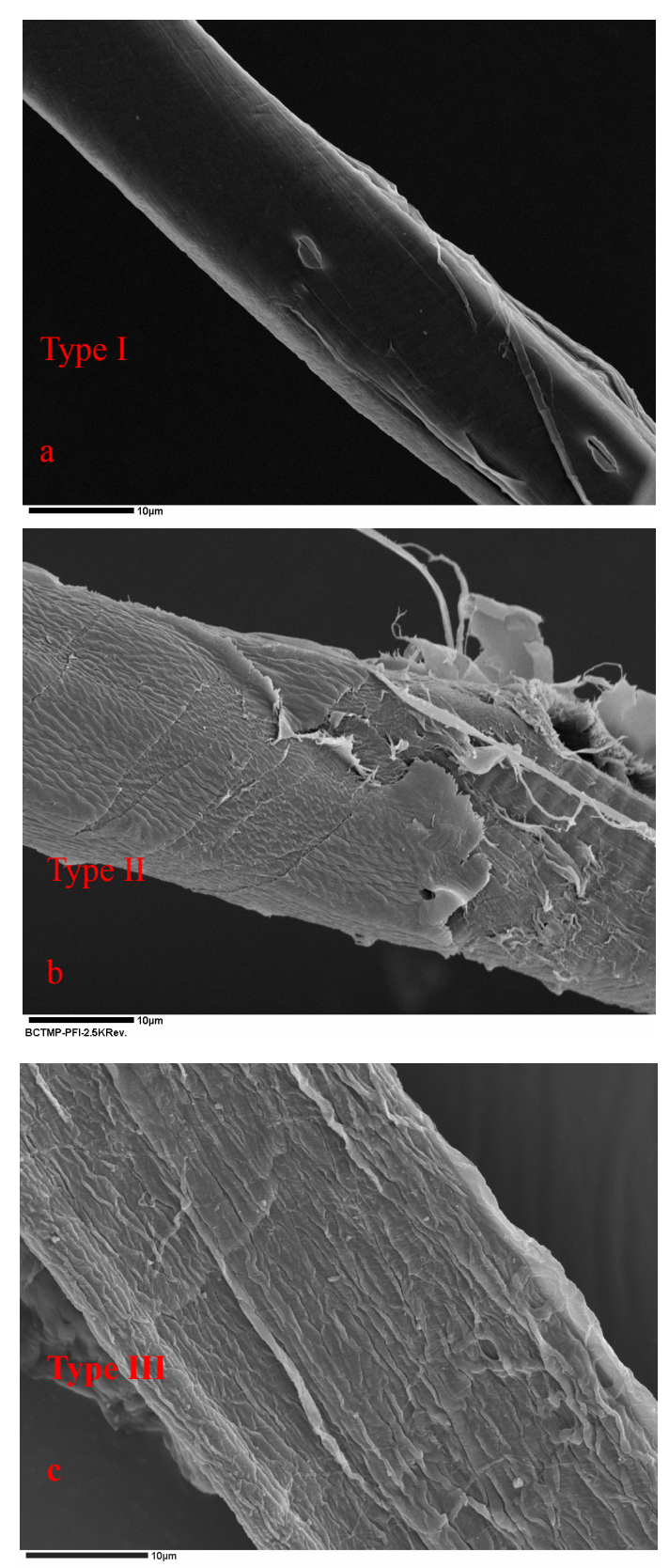

Figure 1. Typical Surfaces of wood pulp fibers. (a) ACTMP, (b) AHB, and (c) SBKPPFI 

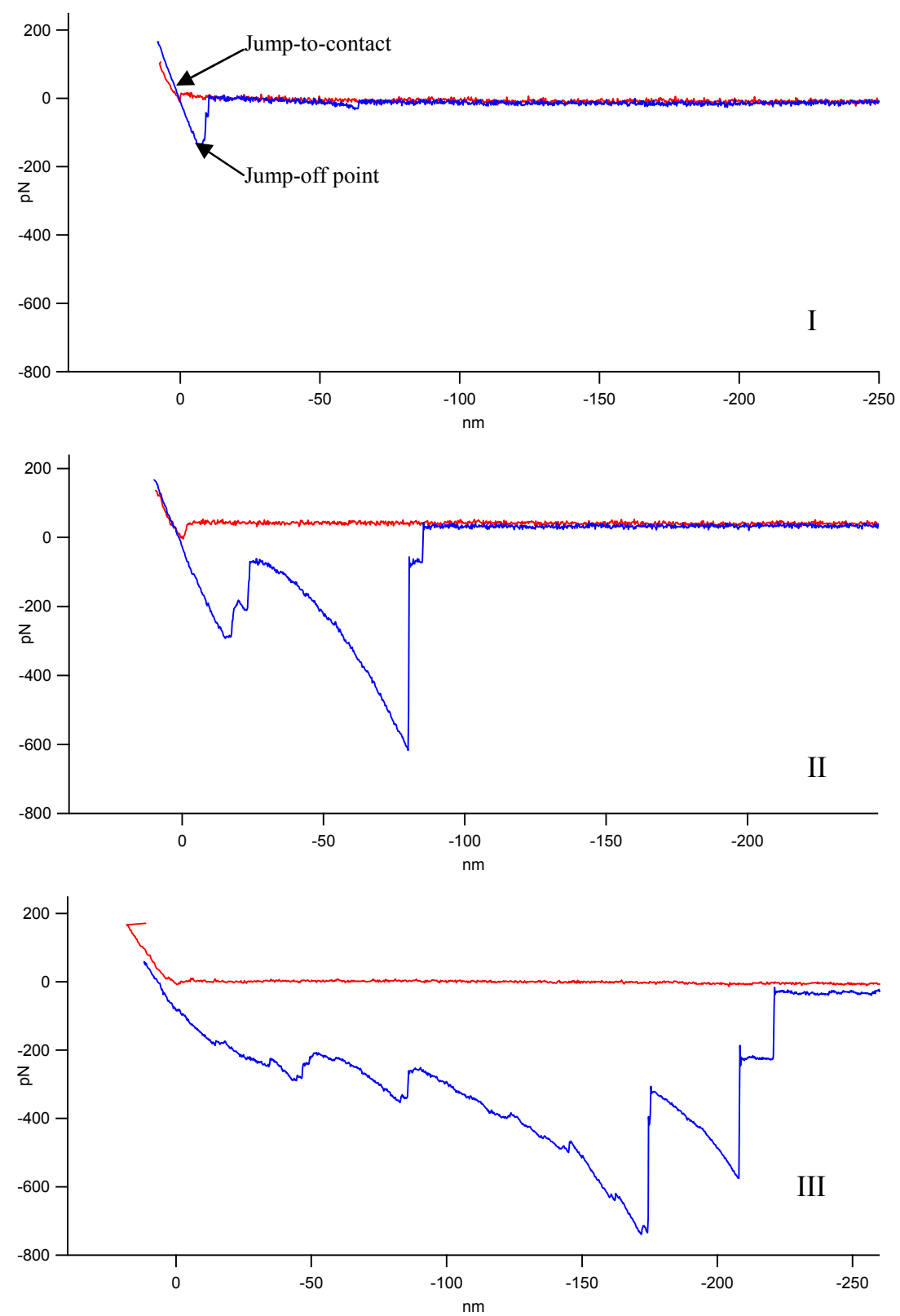

Figure 2. AFM retraction curves and schematics showing three types of interactions on fiber surfaces under different conditions. (I) Interactions between the tip and a more solid fiber substrate; (II) interactions between the tip and a swollen surface; (III) Interactions between the tip and layers of micro-fibrils 


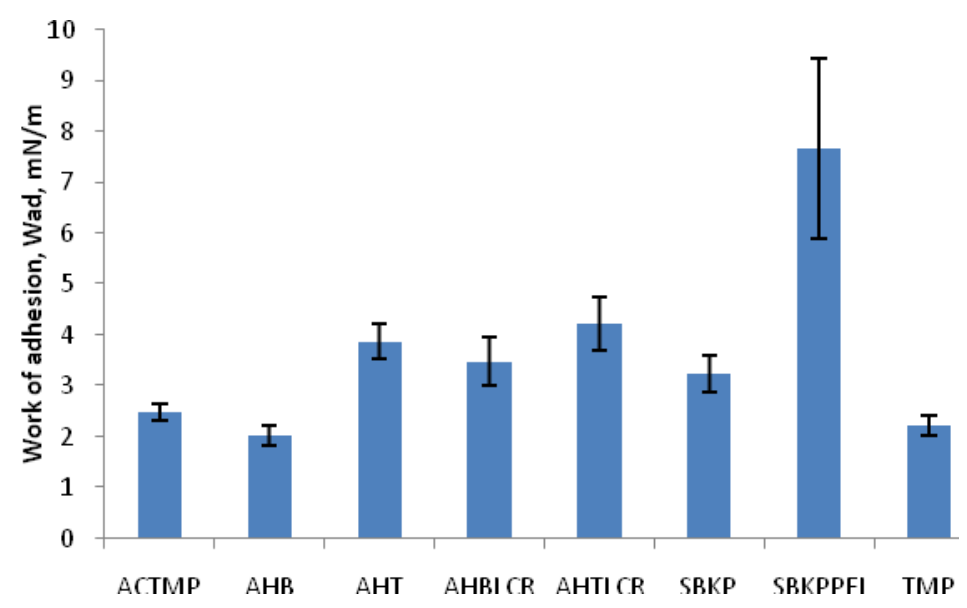

Figure 3. Comparison of work of adhesion between the AFM tip and the fiber surface for type I interactions for tested pulps

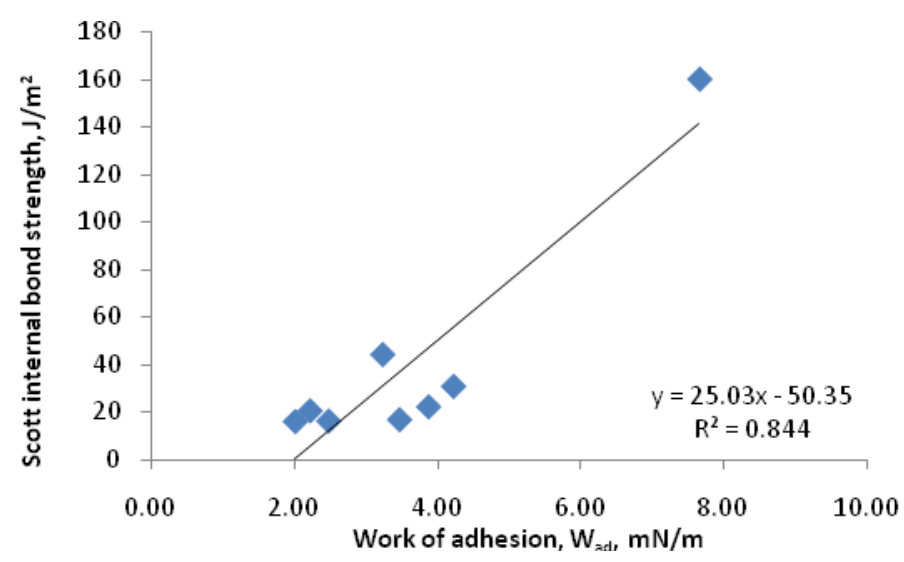

Figure 4. Correlation between work of adhesion measured with the CFM and the Scott internal bond strength of fines-free handsheets

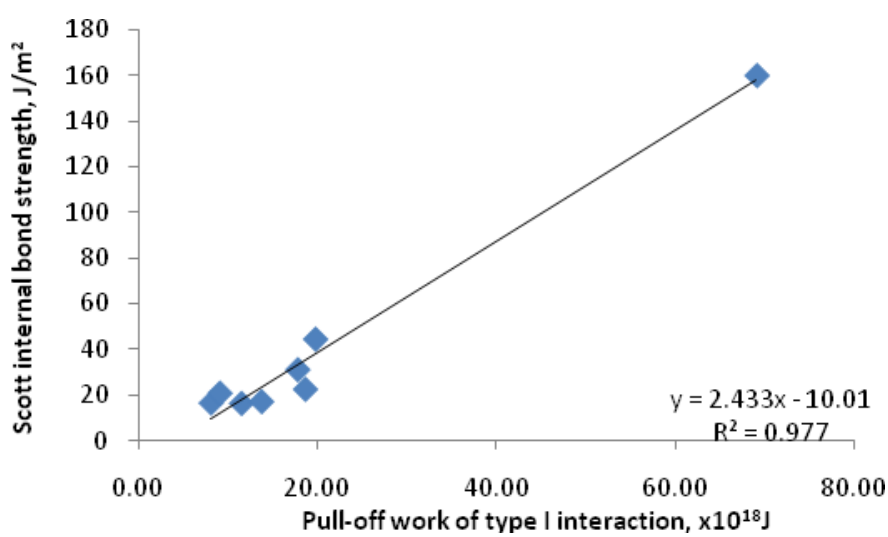

Figure 5. Correlation between pull-off work of type I interactionsand the Scott internal bond strength of fines-free handsheets 


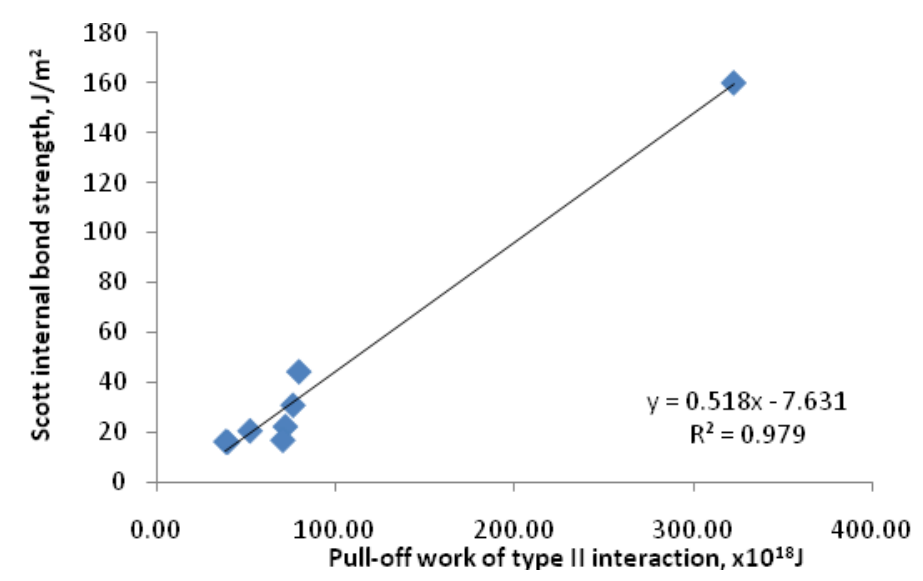

Figure 6. Correlation between pull-off work of type II interaction and the Scott internal bond strength of fines-free handsheets

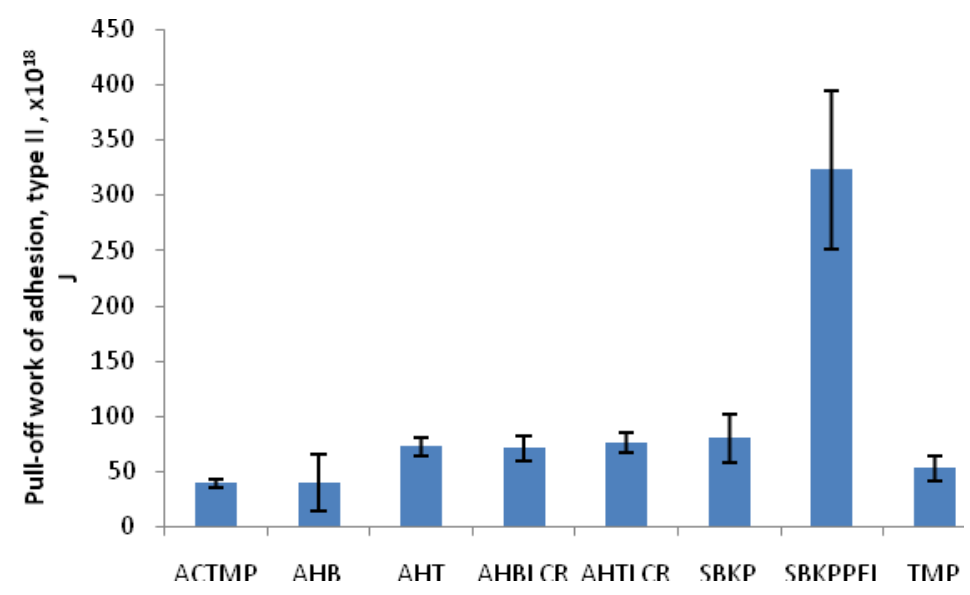

Figure 7. Comparison of pull-off work of type II interactions for the tested pulps

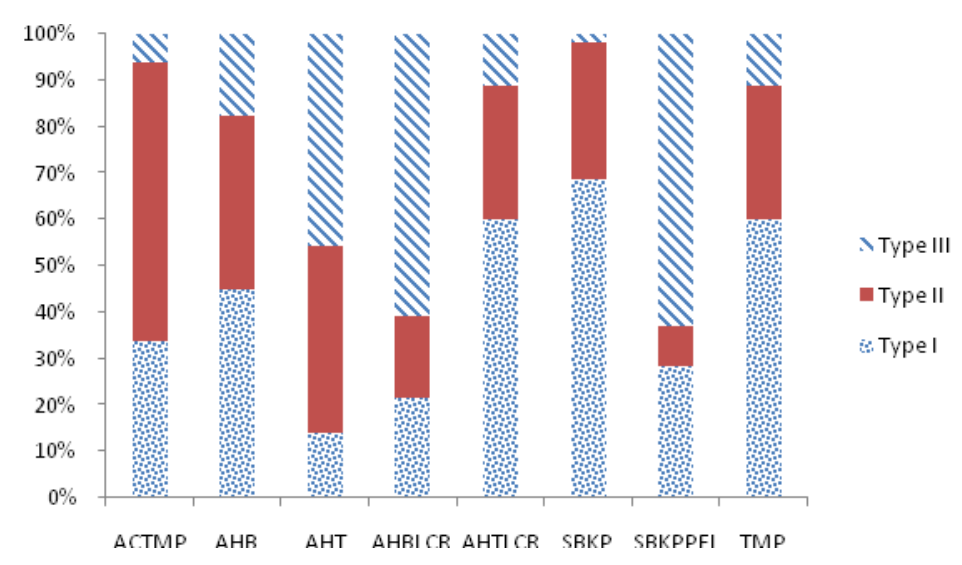

Figure 8. Pecentage of type I, II and III force-displacement curves observed on different pulp fibers

\section{Summary}

Three types of interactions was found between an $-\mathrm{OH}$ functionalized AFM tip and wet fiber surfaces using chemical force microscopy. Each type corresponds to a particular characteristic of fiber surfaces. Type I interactions occur when the tip isin contact with amore solid substrate. It represents the nature of van der Waals 
interactions between the modified tip and fiber surface and is determined mostly by fiber surface chemistry. Type II interactions mainly occur on fiber surfaces having a gel-like compliance layer caused by swelling. The pull-off force of type II interactions is higher than that of type I since hydrogen bonds are more likely to be formed due to the highly deformable fiber surface. Type III interactions show multiple interactions when the tip is pulled off from the surface micro fibrils.

The effects of pulping methods, chemical and mechanical treatments on inter-fiber bonding properties can be well explained through the types of pull-off and the work required to perform these interactions. The chemical treatment of pulp fibers may change inter-fiber bonding properties by altering surface chemistry. However, surface deformability plays a much more important role in determining inter-fiber bonding properties since inter-molecular bonds can only be formed in areas of close contact. External micro fibrils and swelling of the fiber wall improve inter-fiber bonding properties by creating more area for molecular contact.

\section{References}

Bastidas, J. C., Venditti, R., Pawlak, J., Gilbert, R., Zauscher, S., \& Kadla, J. F. (2005). Chemical force microscopy of cellulosic fibers. Carbohydrate Polymers, 62(4), 369-378. http://dx.doi.org/10.1016/j.carbpol.2005.08.058

Chhabra, N., Spelt, J. K., Yip, C. M., \& Kortschot, M. T. (2005). An investigation of pulp fibre surfaces by atomic force microscopy. Journal of Pulp and Paper Science, 31, $52-56$.

Clark, J. A. (1985). Fibrillation and fibre bonding. Pulp technology and treatment for paper (2nd ed., pp. 145-159). San Francisco: Miller Freeman.

Davison, R. W., \& Cates, R. E. (1975). Electrokinetic effects in papermaking systems: Theory and practice. Paper Technol. Ind., 16(4), 107-144.

Feldman, K., Tervoort, T., Smith, P., \& Spencer, D. N. (1998). Toward a force spectroscopy of polymer surfaces. Langmuir, 14(2), 372-378. http://dx.doi.org/10.1021/la9703353

Furuta, T., \& Gray, D. G. (1998). Direct force-distance measurements on wood-pulp fibers in aqueous media. Journal of Pulp and Paper Science, 24(10), 320-334.

Holmberg, M., Berg, J., Stemme, S., Ödberg, L., Rasmusson, J., \& Claesson, P. (1997). Surface force studies of Langmuir-Blodgett cellulose films. Journal of Colloid and Interface Science, 186(2), 369-381. http://dx.doi.org/10.1006/jcis.1996.4657

Isrealachvilli, J. (1991). Intermolecular and surface forces (2nd ed.). San Diego: Academic Press.

Johnson, K. L., Kendall, K., \& Roberts, A. D. (1971). Surface energy and the contact of elastic solids. Proceedings of the Royal Society of London. Series A, Mathematical and Physical Sciences, 324(1558), 301-313.

Klash, A., Ncube, E., \& Meincken, M. (2009a). Localization and attempted quantification of various functional groups on pulpwood fibres. Applied Surface Science, 255(12), 6318-6324. http://dx.doi.org/10.1016/j.apsusc.2009.02.009

Klash, A., Ncube, E., \& Meincken, M. (2009b). Localization and attempted quantification of various functional groups on pulpwood fibres. Applied Surface Science, $255(12), 6318$. http://dx.doi.org/10.1016/j.apsusc.2009.02.009

Li, K., \& Reeve, D. W. (2002). Lignin adsorption on wood fibre surfaces. Proceedings of the 2002 Tappi International Pulp Bleaching Conference, 45-55.

Li, K., \& Reeve, D. W. (2000). The origins of kraft pulp fibre surface lignin. 2000 International Pulp Bleaching Conference: Oral Presentations, 197-202.

Lindstrom, T., Wagberg, L., \& Larrson, T. (2005). On the nature of joint strength in paper-a review of dry and wet strength resins used in paper manufacturing. Trans. 13th Fund. Res. Symp. Cambridge, 457-541.

Mark, R. E. (2002). Determination of fiber-fiber bond properties. In R. E., Mark, C. C., Habeger Jr, J., Borch, \& M. B., Lyne (Eds.), Handbook of physical testing of paper (2nd ed., pp. 873-900). New York, NY: Marcel Dekker.

Michael, J., Bo, F., \& Gorgen, A. (1985). High-yield pulp from north american aspen. Tappi Journal, 68(11), 62-66.

Mohlin, U. (1974). Determination of interfiber bond strength. Svensk Papperstidn, 77(4), 131-137. 
Neuman, R. D., Berg, J. M., \& Claesson, P. M. (1993). Direct measurement of surface forces in papermaking and paper coating systems. Nordic Pulp Paper Research Journal, 8, 96.

Nigmatullin, R., Lovitt, R., Wright, C., Linder, M., Nakari-Setälä, T., \& Gamac, M. (2004). Atomic force microscopy study of cellulose surface interaction controlled by cellulose binding domains. Colloids and Surfaces B: Biointerfaces, 35, 125-135. http://dx.doi.org/10.1016/j.colsurfb.2004.02.013

Nordman, L. S., Gustafsson, C., \& Olofsson, G. (1954). The strength of bonding in paper. Paperi Ja Puu, 36(8), 315-320.

Notley, M. S., Pettersson, B., \& Wagberg, L. (2004). Direct measurement of attractive van der waals' forces between regenerated cellulose surfaces in an aqueous environment. J. Am. Chem. Soc., 126(43), 13930-13931. http://dx.doi.org/10.1021/ja045992d

Noy, A., Vezenov, V. D., \& Lieber, M. C. (1997). Chemical force microscopy. Annu. Rev. Mater. Sci, 27, 381-421.

Osterberg, M., \& claesson, P. J. (2000). Interactions between cellulose surfaces: Effect of solution $\mathrm{pH}$. Adhesion Sci. Techn., 14(5), 603.

Page, D. H., \& Sargent, J. W. (1961). The fine structure of fibre bonding. in the formation and structure of paper. Trans. 2nd Fund. Res. Symp. Oxford., 1, 193-200.

Pan, G. X. (2001). An insight into the behaviour of aspen CTMP in peroxide bleaching, alkalinity's influence is greater than that of peroxide charge. Pulp Pap can, 102(11), 41-45.

Pan, X. (2003). Pulp yield loss in alkaline peroxide bleaching of aspen CTMP part 1: Estimation and impacts. Tappi Journal, 2(9), 27-32.

Papastavrou, G., \& Akari, S. (2000). Interaction forces between OH-groups in different solvents as observed by scanning force microscopy. Colloids and Surface A: Physicochemical and Engineering Aspects, 164(175), 175-181. http://dx.doi.org/10.1016/S0927-7757(99)00403-3

Proksch, R., \& Cleveland, J. (2005). Quantifying molecular forces: Sensitivities and spring constants without touching a surface.

Retulainen, E., \& Ebeling, K. (1985). Effect of paper on the load-elongation behaviour of fiber-to-fiber bonds. Trans. 8th Fund. Res. Symp. Oxford. 229-263.

Retulainen, E., Niskanen, K., \& Nilsen, N. (1998). Fibers and bonds. Paper physics. Helsinki, Finland: Fapet Oy.

Skowronski, J., \& Bichard, W. (1987). Fibre-fibre bonds in paper. part I. measurement of bnd strength and specific bond strength. J. Pulp Paper Sci., 13(5), J165.

Tan, X., \& Li, K. (2008). Adhesion force between lignocellulose material. J. Pulp Paper Sci., 34(2), 77-85.

Theo G. M., \& van de Ven. (2008). Capillary forces in wet paper. Industrial \& Engineering Chemistry Research, 47(19), 7250-7256.

Uesaka, T. (1984). Handbook of physical and mechanical testing of paper and paperboard. In R. E. Mark (Ed.), (pp. 379-402). New York: Marcel Dekker.

Vezenov, V., Dmitri Noy, A., Rozsnyai, F., Lawrence, L., \& Charles, M. (1997). Force titrations and ionization state sensitive imaging of functional groups in aqueous solutions by chemical force microscopy. $J$. Am. Chem. Soc., 119, 2006-2015. http://dx.doi.org/10.1021/ja963375m

Willing, A. G., \& Neuman, D. R. (2002). Analysis of asperity-asperity adhesion forces utilizing statistical analysis techniques and the force selectivity of the scanning probe microscope. Langmuir, 18, 8370-8374. http://dx.doi.org/10.1021/la0114474

Zauscher, S., \& Klingenberg, J. D. (2000). Normal forces between cellulose surfaces measured with colloidal probe microscopy. Journal of Colloid and Interface Science, 229, 497-510. http://dx.doi.org/10.1006/jcis.2000.7008 